\title{
Occupational exposure to pesticides as a possible risk factor for the development of chronic diseases in humans (Review)
}

\author{
SILVIA GANGEMI $^{1^{*}}$, EDOARDO MIOZZI ${ }^{*}$, MICHELE TEODORO ${ }^{1}$, GIUSI BRIGUGLIO ${ }^{1}$, \\ ANNAMARIA DE LUCA ${ }^{1}$, CARMELA ALIBRANDO ${ }^{1}$, IRENE POLITO $^{1}$ and MASSIMO LIBRA ${ }^{2}$ \\ ${ }^{1}$ Department of Biomedical, Odontoiatric, Morphological and Functional Images, Occupational Medicine Section, \\ 'Policlinico G. Martino' Hospital, University of Messina, I-98125 Messina; ${ }^{2}$ Department of Biomedical \\ and Biotechnological Sciences, Laboratory of Translational Oncology and Functional Genomics, \\ Section of General and Clinical Pathology and Oncology, University of Catania, I-95124 Catania, Italy
}

Received June 2, 2016; Accepted September 30, 2016

DOI: $10.3892 / \mathrm{mmr} .2016 .5817$

\begin{abstract}
It is well known that pesticides are widely used compounds. In fact, their use in agriculture, forestry, fishery and the food industry has granted a huge improvement in terms of productive efficiency. However, a great number of epidemiological surveys have demonstrated that these toxic compounds can interact and exert negative effects not only with their targets (pests, herbs and fungi), but also with the rest of the environment, including humans. This is particularly relevant in the case of workers involved in the production, transportation, preparation and application of these toxicants. Accordingly, a growing body of evidence has demonstrated the correlation between occupational exposure to pesticides and the development of a wide spectrum of pathologies, ranging from eczema to neurological diseases and cancer. Pesticide exposure is often quite difficult to establish, as many currently used modules do not take into account all of the many variables that can occur in a diverse environment, such as the agricultural sector, and the assessment of the real risk for every single worker is problematic. Indeed, the use of personal protection equipment is necessary while handling these toxic compounds, but education of workers can be even more important: personal contamination with pesticides may occur even in apparently harmless situations. This review summarises the most recent findings describing the association between pesticide occupational exposure and the development of chronic diseases.
\end{abstract}

Correspondence to: Dr Silvia Gangemi, Department of Biomedical, Odontoiatric, Morphological and Functional Images, Occupational Medicine Section, 'Policlinico G. Martino' Hospital, University of Messina, Via Consolare Valeria, I-98125 Messina, Italy E-mail: silviagangemi@hotmail.com

*Contributed equally

Key words: pesticides, chronic diseases, occupational exposure, exposure assessment, risk assessment

\section{Contents}

1. Introduction

2. Pesticide risk assessment

3. Use of job-exposure matrices and quantitative algorithms

4. Epigenetics

5. Diabetes mellitus

6. Neurological diseases

7. Reproductive disorders

8. Cancer

9. Conclusions

\section{Introduction}

Different environmental exposures during work activities may affect the health conditions of workers, although they use the personal protective equipment in agreement with the current regulations (1-3). Several examples of the adverse effects linked with such occupational exposures have been observed in our previous studies (4-14). All of these effects may cause biomolecular alterations, resulting in the development of specific diseases (15-20). An example of occupational environmental exposure is that of the agricultural setting where pesticides are commonly used (21-23). Many components included in pesticides are apparently not toxic to humans $(24,25)$; however, studies have demonstrated that chronic exposure to pesticides may be a risk factor for microenvironment perturbation and for the development of chronic diseases $(26,27)$.

Humans are exposed to pesticides though occupational or environmental exposure. In the first case, rural workers, greenhouse workers, workers in pesticide manufacture, mixing or application, bystanders, are considered the group that receive the greatest exposure, by mixing, loading, transporting and applying pesticides. Furthermore, many workers, particularly in developing countries, are not adequately informed about the risks associated with the use of pesticides, and the lack of training and equipment to safely handle pesticides increases the health risk (28).

As regards environmental exposure, this mainly affects the general population through the consumption of polluted 
food and drinking contaminated water or using pesticides in the home or living close to sprayed fields. Thus, risk assessment and prevention from pesticide exposure is not a simple process, particularly when we consider several limitations, such as differences in the time and the levels of exposure, the class of pesticides (as regards chemical structure and toxicity), mixtures or cocktails used, and the geographical and climate features of the areas where pesticides are applied.

For these reasons, it has been suggested that pesticide safety should be tested before and after marketing, in order to evaluate whether the estimated or predicted individual exposure on a given task is suitable (29).

Furthermore, the use of human epidemiological studies can improve the efficacy and strength of the risk assessment process, as epidemiological data represent the most direct evidence of an association between health effects and pesticide exposure (30).

On this ground, this review first summarises the risk assessment and management for workers exposed to pesticides and then focuses on the association between occupational exposure to pesticides and the occurrence of chronic diseases (Table I).

\section{Pesticide risk assessment}

Due to the potential toxic effects of pesticide exposure, both acute and chronic, it is important to determine the amount of active principle to which a worker is exposed during his/her occupational activities. However, this is not always simple (31), either due to the fact that in rural areas, the separation between the working environment and the living one is not well-defined, as fields can be very close to farmers' houses, or due to other confounding factors.

The use of personal protective equipment has always been considered fundamental for the safety of workers, as firstly suggested by Libich et al (32), who reported a significant reduction in the urinary levels of herbicide metabolite in pesticide applicators, following an educational path on the hazards of dermal contact with pesticides and the implementation of personal protection equipment (PPE) in their working routine.

Interestingly, Arbuckle et al (33), in a study conducted on a population of farm workers in Ontario, did not highlight any significant correlation between the use of pesticides and the implementation of PPE in individual working routines, with the exception for the use of gloves or face shields during the application of 2,4-dichlorophenoxyacetic acid (2,4-D).

Environmental monitoring is often not reliable for the determination of pesticide exposure due to certain, such as climate changes and variables in the use of these substances by the operators. In this regard, a study performed in northern Italy (34) provided some interesting evidence. The study was conducted on 11 rice and 13 maize farms in Lombardy (Italy), which had a small number of workers (3 or 4), and participated in the study with one worker only, who was in charge for pesticides application. Since the main route of pesticide absorption is cutaneous (35-37), the exposure was assessed by using pads (skin exposure) and by washing workers' hands at the end of the working shift with $200 \mathrm{ml}$ of iso-propanol. The hand wash liquid was collected for analysis (hand skin exposure) according to the Organization for Economic Cooperation and Development (OECD) guidelines (38). A 24-h urine collection was performed for biomonitoring. The study results showed a non-linear relationship between parameters, such as the amount of pesticides used and the amount of pesticides found on the workers' clothes, between the amount of pesticides on the clothes and the amount of pesticides on workers' skin, and, finally, between the amount of pesticides excreted in the urine and the amount found on the skin. Furthermore, authors demonstrated an inverse correlation between the size of the estate and the levels of workers' exposure, similar to the results obtained by Baldi et al (39).

As suggested by the above-mentioned previous study (34), real values of exposure to pesticides are not always easily predictable. A recent study conducted in France, the PESTEXPO study (40), highlighted workers' specific tasks as another important determinant regarding exposure to pesticides. Occupational exposure to pesticides, in fact, is usually associated only with the mixing of these substances, transportation, application to crops and cleaning of the equipment. Actually, exposure to pesticides can occur in other situations, such as the so-called re-entry operations, such as cutting branches and the raising of wires, when operators manipulate plants that can still be contaminated with toxicants. The PESTEXPO study involved vineyard workers of the area of Bordeaux, which is particularly rich in vineyards, and exposure was assessed by the application of patches over the clothes and directly on the skin, changed after every working switch. Hand skin exposure was evaluated by washing the hands with bottled water and collecting the wastewater, similarly to the method by Rubino et al (34). The study examined exposure levels during various re-entry activities and during the harvest, finding that contamination with pesticides is maximal when raising wires and cutting branches (among re-entry activities) and when picking grapes during the harvest. A lower level of exposure was registered when re-entry activities followed pesticide application by more than one week, even if no statistically significant correlation was found between workers' contamination and time since treatment. Furthermore, gender appeared to be the only worker's characteristic associated with different contamination, with the female median contamination much higher than that of the male one, and other elements such as humidity, previous rainfalls, and the characteristics of the crops and the estate appeared to be significant. This study demonstrated the importance of taking into account other activities such as harvesting and re-entry operations for a proper estimate of worker's exposure, adding complexity to the estimate of risk.

Over time, studies such as the PESTEXPO study and others have proposed new models to forecast workers' specific risk (41), even if it is still difficult to determine the effectiveness of the estimation of exposure, convenience and costs.

\section{Use of job-exposure matrices and quantitative algorithms}

A great number of environmental and biological monitoring methods have been improved to estimate human exposure to pesticides.

Over the past decade, it has become clear that it is necessary to develop new approaches for evaluating the safety of a pesticide before its introduction to the market (pre-marketing risk assessment and management) and during its use in industry and agriculture (post-marketing risk assessment and management) (29). 
The pre-marketing risk assessment of pesticides is based on toxicological studies in order to evaluate the predicted exposure of the operator, taking into account the typical conditions of pesticide application. However, authors have revealed some limitations: the majority of toxicological studies are based on tests performed on animals which were exposed to high levels of a single pesticide at a time; the examined conditions of application are not absolutely representative of the variability of scenarios, cultures and exposure conditions of all geographical areas. As regards the post-marketing assessment, it involves occupational exposure measurements in industry and in agriculture and public health. In the industrial setting, it is easy to evaluate such exposure due to the limited number of pesticides involved, whereas, the exposure conditions, the use of mixtures of pesticides, the variety of operator tasks, the environmental conditions and the individual characteristics (use of PPE, personal hygienic behavior, professional training) make the assessment difficult in agriculture and public health (29).

Data from epidemiological studies are not currently used for human risk assessment in a systematic consistent way due to several limitations, such as inadequate exposure characterization, lack of quantitative data, potential confounding factors and any biological plausibility. As epidemiological data represent the most direct evidence of an association between health effects and pesticide exposure, several authors suggest the opportunity of an integrated approach of in vivo, in vitro and in silico data, together with well-designed epidemiological studies (30,41-43).

Another tool in the assessment of the risk due to pesticide exposure is represented by the application of indirect measurements, such as expert's judgment, job questionnaires, calendars and job-exposure matrices (JEMs) (44-46). Even in this case, care must be given to avoid worker's misclassification due to the said great difference in the degree of exposure depending on the worker's task. Due to the different cultural levels among workers and to the wide amount of pesticides used and the different jobs that a single worker may have done in his/her life, self-reported information is not always reliable and requires the judgment of an expert or the consultation of registers and work calendars. The use of JEMs is a valuable resource, particularly when it is difficult to reconstruct an accurate work history regarding exposure to pesticides, as might be the case for retrospective studies. A JEM is compiled taking into account the work done and different exposure parameters, such as intensity and duration, as well as various details about the temporal variations of exposure.

A systematic review (47) summarised various models of JEMs that have been developed over time to assess pesticide exposure. The authors differentiated between JEMs studied specifically for agricultural cohorts, and others that have been produced to assess exposure in the general population.

The comparison between different JEMs (47) led the authors to the conclusion that these tools can be particularly useful to pesticide toxicology, particularly towards the study of the impact of these toxicants in the development of chronic diseases. Even if the results obtained with the use of JEMs look promising, the literature lacks comparisons between these results and those obtained with other exposure assessment methods
Dosemeci et al (48), in a cohort study conducted on more than 58,000 pesticide applicators of North Carolina and Iowa, suggested a quantitative method, based on two algorithms (a 'general' algorithm and a 'detailed' algorithm), in order to evaluate long-term chemical-specific pesticide exposure. Occupational data were obtained using an enrolment questionnaire and a detailed take-home questionnaire, to estimate possible selection bias for the subcohort in terms of differences in pesticide exposure levels. The weighting factors applied in both algorithms were calculated using measurement data from the published pesticide exposure literature and professional judgement. The distribution patterns of all basic exposure indices (i.e., intensity, duration and cumulative exposure to 2,4-D and chlorpyrifos) by state, gender, age and applicator type were almost equal in two study populations, demonstrating that the take-home questionnaire subcohort of applicators is characteristic of the entire cohort in terms of exposure. Despite the use of different variables for each algorithm, high concordance was detected between the 'general' algorithm and the 'detailed' one, as regards percentage agreement and correlation. The results of that study suggest that this quantitative method can be very helpful to evaluate the risk of developing several chronic diseases in subjects exposed to pesticides (48).

Negatu et al (49) developed two semi-quantitative exposure algorithms to assess cumulative exposure to pesticides in a group of applicators and re-entry workers of different farming systems in Ethiopia. These algorithms were based on detailed exposure factors, including application methods, farm layout (open or closed), pesticide mixing circumstances, the cleaning of spraying equipment, the amount of pesticide application per day, the utilization of PPE, personal hygienic behavior, the annual frequency of application, and the length of employment at the farm. The algorithms assessed the daily, annual and cumulative lifetime exposure for applicators and re-entry workers by farming system, gender and age group; these can be helpful mainly for evaluating acute and chronic health effects in workers exposed to pesticides, particularly in low- and middle-income countries (49).

Nevertheless, establishing the correct level of exposure of an individual is not sufficient for a proper assessment of risk. Individual characteristics may, in turn, determine different levels of susceptibility (genetic or epigenetic) to a chemical compound between different individuals and even in the same individual. For example, cutaneous lesions can greatly increase the percentage dose of pesticides absorbed, and chronic skin pathologies, such as psoriasis can exert a similar effect. In addition, chronic liver diseases can slow down the metabolism of pesticides, resulting in a longer plasmatic half-life and, consequently, in an enhanced toxicity.

\section{Epigenetics}

The term 'epigenetics' refers to alterations in genomic expression that do not involve alterations in DNA. Even if the DNA sequence is not altered, epigenetic alterations can be persistent through several cell division cycles, and can even be inheritable.

Epigenetics has been linked to the development of cancer, and a recent study indicated that epigenetic alterations may be involved in the pathogenesis of diseases as a result of chronic toxic chemical exposure (50). 
Table I. Studies focusing on the assessment of pesticide exposure.

Year Authors/(Refs.) Article type Title Subject

1984 Libich et al (32) Research $\quad$ Occupational exposure of herbicide applicators to herbicides used along electric power transmission line right-of-way

2002 Aprea et al (31) Review

2002 Dosemeci et al (48) Research a review of analytical methods

A quantitative approach for estimating exposure to pesticides in the Agricultural Health Study

2005 Arbuckle et al (33) Research

Biomonitoring of herbicides in Ontario farm applicators

2005 Aprea et al (35) Research

Evaluation of skin and respiratory doses and urinary excretion of alkylphosphates in workers exposed to dimethoate during treatment of olive trees

2006 Baldi et al (39) Research Pesticide contamination of workers in vineyards in France

2006 Maroni et al (29) Research Risk assessment and management of. occupational exposure to pesticides in agriculture

2008 Flack et al (36)

2009 Vitali et al (37)

Research

2012 Colosio et al (41)

Research

2012 Rubino et al (34)

Research

2014 Baldi et al (40)

Research

2016 Peters et al (44)

Research

2016 Alif et al (45)

Review

2016 Milner et al (46)

Research

Development and application of quantitative methods for monitoring dermal and inhalation exposure to propiconazole

Operative modalities and exposure to pesticides during open field treatments among a group of agricultural subcontractors Integration of biological monitoring, environmental monitoring and computational modelling into the interpretation of pesticide exposure data: Introduction to a proposed approach

Farmers' exposure to herbicides in North Italy: Assessment under real-life conditions in small-size rice and corn farms

Levels and determinants of pesticide exposure in re-entryworkers in vineyards: Results of the PESTEXPO study

A Quantitative Job-Exposure Matrix for Five Lung Carcinogens

Occupational exposure and risk of chronic obstructive pulmonary disease: A systematic review and meta-analysis

Validity of a Job-Exposure Matrix for Survey Psychosocial Job Stressors: Results from the Household Income and Labour Dynamics in Australia Survey

2016 Carles et al (47) Review Use of job-exposure matrices to estimate occupational exposure to pesticides: A review
Pesticide exposure routes

Analytical methods for pesticide biological monitoring

A prospective cohort study on more than 58,000 pesticide applicators aimed to develop a quantitative method to estimate long term chemical-specific pesticide exposure

Biomonitoring of pesticide metabolites in the urine of farm applicators

Pesticide exposure routes

Exposure assessment in farm workers with different tasks

A study on the pre-marketing and post-marketing assessment and management of occupational exposure to pesticides as the base for improving health surveillance of exposed workers Pesticide exposure routes

Pesticide exposure routes

Combined approach to estimate worker's pesticide exposure

Herbicide exposure assessment in a population of farmers

Exposure assessment in vineyard workers after re-entry tasks

Development of a JEM for lung carcinogens

Assessment of risk for COPD through the use of JEMs

Development of a JEM

Systematic review of JEMs related to pesticide exposure 
Table I. Continued.

\begin{tabular}{|c|c|c|c|c|}
\hline Year & Authors/(Refs.) & Article type & Title & Subject \\
\hline 2016 & Negatu et al (49) & Research & $\begin{array}{l}\text { A Method for Semi-quantitative } \\
\text { Assessment of Exposure to Pesticides } \\
\text { of Applicators and Re-entry } \\
\text { Workers: An Application in Three } \\
\text { Farming Systems in Ethiopia }\end{array}$ & $\begin{array}{l}\text { A cross-sectional study on farmers } \\
\text { and farm workers, including } \\
\text { applicators and re-entry farmers, } \\
\text { aimed to identify an easily adaptable } \\
\text { semi-quantitative method to assess } \\
\text { pesticide exposure and farm workers } \\
\text { in low- and middle-income countries }\end{array}$ \\
\hline 2016 & $\begin{array}{l}\text { Hernández Jerez } \\
\text { et al (30) }\end{array}$ & $\begin{array}{l}\text { Congress } \\
\text { Abstract }\end{array}$ & $\begin{array}{l}\text { Integrating epidemiological, } \\
\text { mechanistic and experimental } \\
\text { toxicology data for pesticide } \\
\text { risk assessment }\end{array}$ & $\begin{array}{l}\text { Authors suggest an integrated approach } \\
\text { of in vivo, in vitro and in silico data, } \\
\text { together with well-designed } \\
\text { epidemiological studies in order to } \\
\text { improve hazard and exposure } \\
\text { assessments of pesticides }\end{array}$ \\
\hline
\end{tabular}

JEM, job-exposure matrice; COPD, chronic obstructive pulmonary disease.

The most typical epigenetic mechanism is DNA methylation, which consists of the addition of a methyl group on a cytosine nucleotide 5th carbon, when the cytosine is followed by a guanine nucleotide in the DNA sequence ( $\mathrm{CpG}$ island). The hypermetilation of promoters usually produces an inactivation of the following gene transcription $(51,52)$. Other mechanisms include post-translational histone modification, which is thought to alter chromosome structure and function (53), and miRNAs, namely non-coding RNA sequences with regulatory functions towards gene expression (54).

In vitro, animal and human studies have recognised several classes of pesticides that can alter epigenetic markers (55) (Table II).

Collotta et al highlighted how DNA methylation can cause the skewing of an allele, resulting in the expression of only one of the two (paternal or maternal), with possible implication in the metabolism of toxic substances (55). The administration of methoxyclor, an organochlorine used as an insecticide, disrupts the female offspring reproductive capacity by remodelling the expression of sex hormones (56). As regards the regulatory role of epigenetics in pesticide toxicology, Holland et al (57) investigated the role of paraoxonase 1 (PON1), a multifunctional enzyme particularly implicated in the metabolism of organophosphates $(58,59)$. PON1 activity varies significantly among individuals, and several molecular variants of this enzyme are recognised. Pesticide exposure and the consequent oxidative stress both have an impact on PON1 gene polymorphisms (60), and research has indicated that an epigenetic mechanism may be responsible for these alterations $(61,62)$.

In a recent case-control study, Howard et al demonstrated an increase in DNAmethylation at $36 \mathrm{CpG}$ sites in a group of Latino farmworkers compared to a sample of 60 Latino non-farmworkers. The authors for the first time analysed gene-specific, genome-wide DNA methylation in subjects occupationally exposed to pesticides, and their results suggest that there is a single epigenetic profile in farmworkers over the growing season, compared to non-farmworkers. A variety of 72 genes may be involved, supporting the hypothesis that alterations in DNA methylation may affect several biologicalpathways and potential disease development (63).

\section{Diabetes mellitus}

Diabetes mellitus (DM) is a disease characterised by chronic hyperglycaemia due to absolute or relative insulin deficiency, resistance, or both. Two patterns of diabetes are commonly recognised: DM type 1, characterised by early onset in life and a likely autoimmune pathogenesis, and DM type 2, by far the most common form, with a later onset in life and a multifactorial pathogenesis.

Nowadays, DM type 2 is one of the most common chronic diseases in first world countries with 415 million individuals affected, and its incidence is expected to increase in the following years (64). Even though individuals affected by diabetes can lead a normal life due to pharmacological therapy, long-term complications are still very common and include cardiovascular, neurological and renal diseases. Obviously, the health-related costs of diabetes are extremely high.

Epidemiological studies have suggested that the pathogenesis of DM is multifactorial, involving both genetic and lifestyle risk factors: a poor unhealthy diet and obesity, a sedentary lifestyle and cigarette smoking can contribute to the pathogenesis of the disease (65).

Over the past years, pesticides, as well as other environmental factors, have been indicated as possible co-factors in the pathogenesis of DM (66-68) (Table III). A systematic review analysed the link between pesticides, DM, and diabetes-related pathologies (69), based on the increasing prevalence of both DM2 and the use of pesticides in Asia. The results, even if often suggestive of a potential link, were nevertheless inconclusive due to the lack of a proper assessment of exposure or other confounding factors.

Another systematic review (70) pointed out a very likely association between certain types of pesticides, in particular organochlorines and organophosphates, and the development of DM. Even if suggestive, the results of the reviewed studies 
Table II. Studies focusing on the interaction between epigenetics and pesticides.

\begin{tabular}{lllll}
\hline Year & \multicolumn{1}{c}{ Authors/(Refs.) } & Article type & Title & Subject \\
\hline $2002 \begin{array}{l}\text { Orphanides and } \\
\text { Reinberg (51) }\end{array}$ & Review & A unified theory of gene expression & New hypothesis about gene expression \\
2003 & $\begin{array}{l}\text { Grewal and } \\
\text { Moazed (52) }\end{array}$ & Review & Heterochromatin and epigenetic & $\begin{array}{l}\text { Regulation of gene expression } \\
\text { control of gene expression }\end{array}$ \\
2003 & Lee et al (58) & Research & $\begin{array}{l}\text { Association between human paraoxonase } \\
\text { gene polymorphism and chronic symptoms } \\
\text { in pesticide-exposed workers }\end{array}$ & $\begin{array}{l}\text { Paraoxonase polymorphism in } \\
\text { pesticide-exposed workers }\end{array}$
\end{tabular}

2005 Robertson (61) Review

2007 Kouzarides et al (53) Review

2007 Jackson and Standart (54)

2011 Stouder and Paoloni- Research Giacobino (56)

2011 Matthews et al (59) Review

2013 Collotta et al (55) Review

2013 Tammen et al (62) Review

2015 Holland et al (57) Review

2015 Costa et al (60)

Research

2016 Howard et al (63)

Research
DNA methylation and human disease

The epigenetic role of DNA methylation in DNA expression

How do microRNAs regulate

Specific transgenerational imprinting effects of the endocrine disruptor methoxychlor on male gametes

Serum paraoxonase 1 (PON 1) genotype and exposure to organophosphorous insectides - is there a high-risk population?

Epigenetics and pesticides modifications

Epigenetics: The link between nature and nurture

Recent progress in the genetics and epigenetics of paraoxonase: Why it is relevant to children's environmental health

Oxidative stress biomarkers and paraoxonase 1 polymorphism frequency in farmers occupationally exposed to pesticides

Changes in DNA methylation over the growing season difference between North Carolina farmworkers and non-farmworkers
The role of microRNAs in gene expression? gene expression Endocrine-disrupting effects of pesticides

Interaction between POn-1 enzyme and organophosphates

Pesticide-induced epigenetic

Interactions between environment and epigenetic modifications Implication of pareoxonase in pesticide-mediated chronic effects

Evaluation of PON-1

polymorphism in a group of farmers exposed to pesticides

A case-control study on the effects on DNA methylation of pesticide exposure in a group of Latino farmworkers were criticised by the authors due to the multifactorial pathogenesis of diabetes, which is a confounding factor that is not always considered during experimental studies.

An interesting aspect pointed out by Leso et al was that many of the studies examined the retrospectively addressed mortality rates for diabetes, while only a few studies assessed early disturbances, such as impaired glucose tolerance, which would be of particular interest as regards prevention (70).

\section{Neurological diseases}

Even if there is not a consensus about the causal role of pesticides in the development of neurodegenerative disorders, increasing evidences has indicated an association between occupational and environmental exposure to these toxicants and the development of neurological diseases (71) (Table IV). Amongst these diseases, Parkinson's disease (PD), Alzheimer's disease (AD) and amyotrophic lateral sclerosis (ALS) seem to be the most likely to be associated with the neurotoxic effects of pesticides. Discovered by James Parkinson in 1817, PD is clinically characterised by the onset of progressive tremors, rigidity and akinesia, the severity of which gradually increases over the years. AD is the most common form of dementia, of which the most important features are a slow onset with a progressive loss of the ability to learn, retain and process information, apraxia, agnosia, the progressive loss of executive function and behavioural changes. ALS is also a progressive disease, which leads to spastic tetraparesis or paraparesis with the addition of lower motoneurone signs (72-74).

A recent meta-analysis (75) confronted several systematic reviews, which correlated the exposure to pesticides with neurodevelopmental disorders in children or major clinical outcomes, such as PD and AD in adults, aiming to establish a better assessment of risk for individuals exposed to these 
Table III. Studies focusing on pesticide exposure and the incidence of diabetes.

\begin{tabular}{|c|c|c|c|c|}
\hline Year & Authors/(Refs.) & Article type & Title & Subject \\
\hline 2008 & Montgomery et al (67) & Research & $\begin{array}{l}\text { Incident diabetes and pesticide exposure } \\
\text { among licensed pesticide applicators: } \\
\text { Agricultural Health Study, 1993-2003 }\end{array}$ & $\begin{array}{l}\text { Incidence of diabetes in a population } \\
\text { of agricultural workers }\end{array}$ \\
\hline 2011 & $\mathrm{Hu}(65)$ & Review & $\begin{array}{l}\text { Globalization of diabetes: The role of } \\
\text { diet, lifestyle, and genes }\end{array}$ & $\begin{array}{l}\text { Role of different factors in the } \\
\text { increase of diabetes type } 2\end{array}$ \\
\hline 2013 & Malekirad et al (66) & Research & $\begin{array}{l}\text { Neurocognitive, mental health, } \\
\text { and glucose disorders in farmers } \\
\text { exposed to organophosphorus pesticides }\end{array}$ & $\begin{array}{l}\text { Cross-sectional study on workers } \\
\text { exposed to pesticides }\end{array}$ \\
\hline 2014 & Starling et al (68) & Research & $\begin{array}{l}\text { Pesticide use and incident diabetes } \\
\text { among wives of farmers in the } \\
\text { Agricultural Health Study }\end{array}$ & $\begin{array}{l}\text { Diabetes incidence among wives } \\
\text { of farmers, based on a previous } \\
\text { study in Iowa }\end{array}$ \\
\hline 2015 & $\begin{array}{l}\text { Jaacks and } \\
\text { Staimez (69) }\end{array}$ & Review & $\begin{array}{l}\text { Association of persistent organic pollutants } \\
\text { and non-persistent pesticides with diabetes } \\
\text { and diabetes-related health outcomes } \\
\text { in Asia: A systematic review }\end{array}$ & $\begin{array}{l}\text { Systematic review on the role of } \\
\text { pesticides and pollutants } \\
\text { in diabetes incidence }\end{array}$ \\
\hline 2016 & Leso et al (70) & Review & $\begin{array}{l}\text { Occupational chemical exposure and } \\
\text { diabetes mellitus risk }\end{array}$ & $\begin{array}{l}\text { Systematic review about the role } \\
\text { of occupational exposure to } \\
\text { chemicals and diabetes incidence }\end{array}$ \\
\hline
\end{tabular}

toxic compounds. As regards neurodegenerative disorders, the authors found a correlation between pesticide exposure and AD, particularly in men, probably due to the fact that mens' working activities usually involve a greater exposure to pesticides compared to those of women. The strongest correlation was shown between pesticides (in general) and the development of PD. Nevertheless, even if the association appears clear, it is difficult to narrow the field to a selected group of pesticides as responsible for this disease (75).

A recent study conducted in California (76) evaluated the association between pesticides and PD, with particular attention being paid to avoiding bias, such as ensuring the adequate representativeness of the source population (cases and controls were selected from the same region) and exposure assessment, which considered sources of contamination from the working environment, but also the household and the general environment. The authors found a positive correlation between pesticide exposure and PD and, according to several studies (77-79), noted the importance of individual susceptibility in the assessment of risk when exposed to toxicants. They also confirmed that the PON1 polymorphysms increase organophosphate susceptibility in slow metabolizers, as well as nitric oxide synthase 1 (NOS1) gene variants that could be responsible for an enhanced nitrosative stress pathway. Finally, they indicated that multidrug resistance protein 1 (ABCB1) gene variants may be responsible for organochlorine-induced PD, and that pyrethroid insecticides can alter immune response in HLA-DR variant carriers.

Recently, the use of adverse outcome (AO) pathways (AOPs) represents a potential tool in toxicology and human risk assessment (80). An AOP is defined as the progression from a molecular initiating event (MIE; a direct interaction of a chemical with its molecular target) through subsequent responses at cellular, tissue, organ and individual organism levels, leading to an AO that is important to risk assessment and regulatory decision-making (81). The European Food Safety Authority (EFSA) suggest that the AOPs share several pragmatic characteristics which make them useful to better identify a possible relationship of cause and effect between exposure to pesticides and PD. In PD, many different AOPs can be identified; but for several specific characteristics, the 'parkinsonian motor symptoms' were selected as the AO (82). In this regard, the overall weight of evidence indicates a significant correlation between the MIE and the AO in PD. A better understanding of key events and key event relationships will make it possible for researchers to use all available data in order to assess the risk and recognise possible causal relationship between exposure to specific pesticides and PD (71).

A meta-analysis in 2012 (83) examined the correlation between pesticide exposure and the development of ALS, and the results showed a positive link with exposure to pesticides as a group, particularly with organochlorines. Another meta-analysis (84) tried to evaluate the correlation between ALS and rural areas, with particular attention being paid to assessing pesticide exposure. The authors noted an increased risk of ALS with pesticide exposure and farmer occupation, but not with rural living. Furthermore, the risk related to the use of pesticides had a significant positive association in men.

As regards neurodevelopmental disorders, Hernandez et al (75) found a solid correlation between prenatal exposure to organophosphates and the alteration of mental or psychomotor development, or disorders like pervasive developmental disorder or attention deficit and hyperactivity disorder in preschool and school children $(85,86)$. Other studies correlated maternal exposure to organochlorines and the development of motor or cognitive disorders in children, or pre- and post-natal 
Table IV. Studies focusing on the link between pesticide exposure and neurological diseases.

\begin{tabular}{llll}
\hline Year & Authors/(Refs.) & Article type & \multicolumn{1}{c}{ Title } \\
\hline 2012 & $\begin{array}{l}\text { Freire and } \\
\text { Koifman }(78)\end{array}$ & Review & $\begin{array}{l}\text { Pesticide exposure and Parkinson's } \\
\text { disease: epidemiological evidence } \\
\text { of association } \\
2012\end{array}$ \\
& Kamel et al $(83)$ & Review & $\begin{array}{l}\text { Pesticide exposure and amyotrophic } \\
\text { lateral sclerosis }\end{array}$
\end{tabular}

\section{Muñoz-Quezada et al (86) Review}

2013 Dardiotis et al (79)

Review

2014 Gonzalez et al (85)

Review

2014 Kang et al (84)

2014 Wang et al (77)

2016 Elbaz and Moisan (72)

$2016 \operatorname{EFSA}(82)$

2016 Hernandez et al (75)

Review

Research

Review

Research

Review

Neurodevelopmental effects in children associated with exposure to organophosphate pesticides: a systematic review

The interplay between environmental and genetic factors in Parkinson's disease susceptibility: The evidence forpesticides

A systematic review of neurodevelopmental effects of prenatal and postnatal organophosphate pesticide exposure

Amyotrophic lateral sclerosis and agricultural environments: A systematic review

The association between ambient exposure to organophosphates and Parkinson's disease risk

The scientific bases to consider Parkinson's disease an occupational disease in agriculture professionals exposed to pesticides in France

Investigation into experimental toxicological properties of plant protection products having a potential link to Parkinson's disease and childhood leukaemia

Systematic reviews on neurodegenerative disorders neurodevelopmental and linked to pesticide exposure:

Methodological features and impact on risk assessment

2016 Ritz et al (77)

Review

Of Pesticides and Men:

A California Story of Genes and Environment in Parkinson's Disease

2016 Wilks (71)
Congress Pesticides and Parkinson's

Abstract disease - What is the evidence from epidemiological and experimental studies?
Subject

Systematic review about the relation between pesticides and Parkinson's disease

Meta-analysis about the impact of pesticides exposure in the development of ALS

Systematic review on the effects of pesticides exposure in children

Review about the relation between pesticides and Parkinson's disease

Systematic review on the effects of prenatal and postnatal pesticides exposure in children

Systematic review about the impact of pesticides exposure in the development of ALS

Case-control study about the relation between OP exposure and Parkinson's disease

Occupational exposure to pesticides and the incidence of Parkinson's disease

A study based on the adverse outcome pathways (AOPs) in order to investigate the plausible involvement of pesticide exposure as a risk factor for Parkinson's disease

Systematic review on occupational exposure to pesticides and incidence of neurological diseases

\section{Pathways involved in pesticide-induced Parkinson's disease}

The author deals with the use of the OECD Adverse Outcome Pathways as a tool for integration of heterogenous data from different sources (human, animal in vitro) to better define a possible causality between exposure to pesticides and Parkinson's disease exposure to pesticides and the development of autism spectrum disorders; however, factors such as design of the studies did not allow the authors of the meta-analysis to draw any definitive conclusions. 
Table V. Studies focusing on the association between pesticide exposure and reproductive disorders.

Year Authors/(Refs.) Article type Title Subject

2001 Arbuckle et al (90) Research An exploratory analysis of the effect of pesticide exposure on the risk of spontaneous abortion in an Ontario farm population

2004 Hanke and Jurewicz (88)

Review

The risk of adverse reproductive and developmental disorders due to occupational pesticide exposure: an overview of current epidemiological evidence

Review

Occupational exposure associated with reproductive dysfunction

2007 Jurewicz and (92) Review Hanke

Risk of reproductive disorders in greenhouse workers

2008 Jurewicz et al (91) Research

2012 Reynolds and Caton (87)

2014 Neghab et al (96)

Research

2015

Miranda-Contreras et al (93)

2015

Radwan et al (94)

2015 Jamal et al (95)
Research
Research
Low risk of reproductive disorders among female greenhouse workers-safe work conditions or health selection for the light work?

Review

Role of the pre- and postnatal environment in developmental programming of health and productivity

The effects of exposure to pesticides on the fecundity status of farm workers resident in a rural region of Fars province, southern Iran

Research

Effects of occupational exposure to pesticides on semen quality of workers in an agricultural community of Merida state, Venezuela

The association between environmental exposure to pyrethroids and sperm aneuploidy

The influence of organophosphate and carbamate on sperm chromatin and and reproductive hormones among pesticide sprayers
The impact of pesticide exposure on spontaneous abortion in a population of women

The risk of pathological alterations on offspring due to parent's pesticide exposure

The harmful effects of pesticide exposure on the reproductive system

A literature review about the association of greenhouse work and reproductive disorders

Impact of hard work and pesticide exposure on pathological pregnancy in a population of greenhouse women workers

The role of developmental insults on offspring

A study regarding the prevalence of reproductive disorders in a population of male and female subjects in Iran

A case-control study aimed at investigating the association between occupational exposure to pesticides and semen quality in a group of farmers stratified by age

A study aimed at evaluating whether the environmental exposure to pyrethroids is associated with male sperm chromosomal disomy

A study aimed at evaluating the association between occupational exposure to organophosphate and carbamate pesticides and semen quality, as well as the levels of reproductive and thyroid hormones in a group of pesticide sprayers in Malihabad

\section{Reproductive disorders}

There is strong evidence to suggest that certain environmental conditions can have a long-term impact on human health, particularly on the male and female reproductive systems, before birth or during infancy (87).

The link between occupational and environmental pesticide exposure has been widely evaluated and studies have demonstrated that exposure to pesticides can impair fertility in both male and female subjects $(88,89)$ (Table V).

A study conducted in Ontario examined the correlation between pesticide exposure in farms and spontaneous abortion. The authors observed a moderate risk of early abortions for preconception exposures to phenoxyacetic acid herbicides, triazines and any herbicide. They also noted that pre-conceptional exposure to a miscellaneous class of 
Table VI. Studies focusing on the link between pesticide exposure and cancer.

\begin{tabular}{lccl}
\hline Year & Authors/(Refs.) & Article type & Title \\
\hline 2013 & Costa et al $(108)$ & Research & $\begin{array}{l}\text { Cytokine patterns in greenhouse } \\
\text { workers occupationally exposed to } \\
\end{array}$ \\
& & $\begin{array}{l}\alpha \text {-cypermethrin: An observational study } \\
\end{array}$
\end{tabular}

\section{Doolan et al (102) Review}

2014 Fenga et al (107)

Research

IL-17 and IL- 22 serum levels in greenhouse workers exposed to pesticides
An update on occupation and prostate cancer
Research

Leon (100)

2015

Del Pup et al (99) Review

2016

Lewis-Mikhael Review
et al $(101)$

et al (101)

2016

Gangemi et al (27)

Review

2016

Hernández and $\quad$ Review
Menéndez (106)

Endocrine disruptors and female cancer: Informing the patients (Review)

Non-Hodgkin lymphoma and occupational exposure to agricultural pesticide chemical groups and active ingredients: a systematic review and meta-analysis

patients (Review)

Occupational exposure to pesticides and prostate cancer: A systematic review and meta-analysis

Occupational and environmental exposure to pesticides and cytokine pathways in chronic diseases (Review)

\author{
Linking Pesticide Exposure with \\ Pediatric Leukemia: Potential \\ Underlying Mechanisms
}

Occupational exposure and risk of breast cancer

Subject

The authors support the hypothesis that pyrethroid exposure may reduce host defenses against infection and cancer, particularly in subjects with impaired immune capacity

The authors review occupational exposures and related factors associated with the risk of prostate cancer and they supported the involvement of polychlorinated biphenyls (PCBs) in prostate cancer

The authors investigate IL-17 and IL-22 alterations in serum of subjects exposed to pesticides, supporting the hypothesis that exposure to pesticides may reduce host defenses against infections and cancer

This research describes results from a systematic review and a series of meta analyses of nearly three decades worth of epidemiological research on the association between non-Hodgkin's lymphoma (NHL) and occupational exposure to agricultural pesticides

The review investigates the effects of endocrine disruptors, including pesticides, on female neoplasms (breast, ovarian and endometrial cancer)

A systematic review to assess the potential association between different degrees of exposure to pesticides and the risk of prostate cancer

The review focuses on the immunotoxicity of pesticides and the development of several chronic diseases, including cancer

The authors review the available experimental and epidemiological evidence linking pesticide exposure to infant and childhood leukemia and provide a mechanistic basis to support the association

A review investigating occupational exposure to several risk factors, including pesticides, and the risk of breast cancer pesticides, thiocarbamates and glyphosate, was linked with a high-risk of late abortion (90). By contrast, a study performed on a population of female greenhouse workers did not reveal any significant association between exposure to pesticides and the occurrence of pre-term delivery, spontaneous abortion and birth defects (91).

As regards male subjects, exposure to pesticides can affect semen quality, sperm parameters (concentration, morphology, 
motility), sex hormone blood levels or the structure of the testes.

Jurewicz and Hanke showed a mean decrease in sperm count in men who were employed in greenhouses for more than ten years (92).

A comparative study performed in Venezuela by Miranda-Contreras et al analysed the sperm quality in farmers exposed to pesticides, showing significant variations of main semen characteristics in exposed subjects, such as a decrease in sperm concentration, reduced motility and alterations in the sperm membrane (93). Pyrethroids may cause sperm aneuploidy (94). Organophosphates and carbamates can act on semen quality and sex hormones, increasing thyroid-stimulating hormone (TSH) and luteinizing hormone (LH) blood levels (95).

A recent study compared a population of randomly selected couples, in which the man was employed on a farm, and the rest of the local population. The results revealed a higher prevalence of primary infertility, along with more frequent stillbirths and spontaneous abortion in farm working couples (96).

\section{Cancer}

The correlation between human pesticide exposure and the development of cancer has been a subject of great interest to the scientific community during the last half of the century, including the International Community for Research on Cancer (IARC) (Table VI).

Cancer is a multifactorial disease resulting from the exposure to several risk factors, including lifestyle habits (97). Even if neoplasms at different sites have been related to pesticide exposure, it is difficult to identify the specific role of a single pesticide in the development of these pathologies, particularly at low doses of exposure.

A review published in 2008 discussed the link between environmental and occupational exposure to harmful stimuli and cancer, observing an increased risk of leukaemia in subjects exposed to organochlorines (98). A correlation was also noted between pesticide exposure and lung cancer, multiple myeloma, non-Hodgkin's lymphoma, ovarian cancer, prostate cancer, rectal cancer, testicular cancer and skin cancer (27). Other studies have highlighted the role of environmental endocrine disruptors in female cancer (99), occupational exposure and breast cancer (14), non-Hodgkin's lymphoma (100) and prostate cancer $(101,102)$.

These environmental stimuli may induce the involvement of the p53, Raf/MEK/ERK and PI3K/AKT pathways in the majority of these cancers, providing giving further insight into the mechanisms of malignant transformation (103-104).

Chronic low-dose exposure, in particular, is thought to be responsible for pre-natal and early post-natal alterations in children. A recent study (106) suggested a possible role of pesticides in the development of infant and pediatric leukaemia, the most common type of cancer in children, through interaction with DNA enzymes such as topoisomerase II and oxidative stress-induced DNA damage.

Among the potential mechanisms of cancerogenesis induced by pesticide exposure, it has been reported that pesticides can alter the immune system, leading to chronic inflammation and the increased production of inflammatory chemokines and cytokines (22).

In support of this suggestion, a cross-sectional study investigated the levels of IL-17 and IL-22 in a cohort of greenhouse workers occupationally exposed to several pesticides (neonicotinoids, pyrethroids and ogranophosphates). The result revealed a significant increase in IL-22 values, while IL-17 did not show significant alterations (107). These findings suggest a possible role of immune deregulation in pesticide-induced pathologies and cancer development. Another study by the same authors noted the potential role of altered immunity in the development of chronic diseases for workers exposed to pesticides (108).

\section{Conclusions}

The aim of this review was to evaluate the impact of pesticides on human health, particularly as regards the development of chronic diseases. Some pesticide-related diseases are extremely common and represent a heavy burden for public health expenditure.

Even though there are many clues pointing towards the association between pesticides, as a group, and the incidence of diseases such as PD, DM or cancer, experimental studies and systematic reviews on the subject are not always conclusive.

The main confounding factor, in our opinion, remains an accurate exposure assessment in epidemiological studies. It has been demonstrated that exposure can vary greatly in the same apparent conditions, even between individuals in the same workplace. Experimental studies and reviews have shown that the most important determinant for personal exposure is a worker's specific task, which can determine consistent deviations from the forecasted exposure values based on environmental data. This, along with personal susceptibility, indicates that some of the values obtained from previous studies based on questionnaires or disease/death registers could be considered not completely reliable.

A proper exposure assessment should, then, be a priority for future studies, with an aim to shed light on the true links between environmental and occupational exposure to pesticides and disease, particularly highly prevalent ones.

\section{References}

1. Valentino M, Rapisarda V and Fenga C: Hand injuries due to high-pressure injection devices for painting in shipyards: Circumstances, management, and outcome in twelve patients. Am J Ind Med 43: 539-542, 2003.

2. Rapisarda V, Valentino M,Bolognini S and Fenga C: Noise-related occupational risk aboard fishing vessels: Considerations on prevention and the protection of exposed workers. G Ital Med Lav Ergon 26: 191-196, 2004 (In Italian).

3. Costa C, Ozcagli E, Gangemi S, Schembri F, Giambò F, Androutsopoulos V, Tsatsakis A and Fenga C: Molecular biomarkers of oxidative stress and role of dietary factors in gasoline station attendants. Food Chem Toxicol 90: 30-35, 2016.

4. Valentino M, Rapisarda V, Scalise L, Paone N, Santarelli L, Fenga $\mathrm{C}$ and Rossi GL: A new method for the experimental assessment of finger haemodynamic effects induced by a hydraulic breaker in operative conditions. J Occup Health 46: 253-259, 2004

5. Rapisarda V, Valentino M, Ravalli P, Fenga C and Duscio D: Occupational brucellosis in slaughtering of sheep and goats: Study of five cases from a municipal abattoir in south-eastern Sicily. Med Lav 96: 134-141, 2005 (In Italian). 
6. Fenga C, Rapisarda V, Valentino M, Cacciola A, Deboli R, Calvo $\mathrm{A}$ and Germanò $\mathrm{D}$ : Hand-arm vibration syndrome and upper limbs diseases in the forest workers of Italia meridionale. G Ital Med Lav Ergon 29 (Suppl 3): 592-593, 2007 (In Italian).

7. Fenga C, Cacciola A, Di Nola C, Calimeri S, Lo Giudice D, Pugliese M, Niutta PP and Martino LB: Serologic investigation of the prevalence of Chlamydophila psittaci in occupationally-exposed subjects in eastern Sicily. Ann Agric Environ Med 14: 93-96, 2007.

8. Fenga C, Di Pietro R, Fenga P, Di Nola C, Spinella R, Cacciola A, Germanò D and Aragona P: Asthenopia in VDT users: Our experience. G Ital Med Lav Ergon 29 (Suppl 3): 500-501, 2007 (In Italian)

9. Fenga C, Platania CA, Di Rosa A, Alibrandi A, De Luca A, Barresi G, Di Nola C and Cacciola A: Mobbing: Between personality traits and organizational-managerial characteristics of the occupational environment. G Ital Med Lav Ergon 34 (Suppl 1A): A11-A16, 2012 (In Italian).

10. Fenga $C$ and Pugliese M: Endemic zoonosis in Mediterranean area. G Ital Med Lav Ergon 35: 347-349, 2013 (In Italian).

11. Fenga C, Aragona P, Di Nola C and Spinella R: Comparison of ocular surface disease index and tear osmolarity as markers of ocular surface dysfunction in video terminal display workers. Am J Ophthalmol 158: 41-48.e2, 2014.

12. Fenga C, Gangemi S, De Luca A, Calimeri S, Lo Giudice D, Pugliese M, Licitra F, Alibrandi A and Costa C: Seroprevalence and occupational risk survey for Coxiella burnetii among exposed workers in Sicily, Southern Italy. Int J Occup Med Environ Health 28: 901-907, 2015.

13. Rapisarda V, Ledda C, Ferrante M, Fiore M, Cocuzza S, Bracci M and Fenga $C$ : Blood pressure and occupational exposure to noise and lead $(\mathrm{Pb})$ : A cross-sectional study. Toxicol Ind Health 32 1729-1736, 2016

14. Fenga C: Occupational exposure and risk of breast cancer. Biomed Rep 4: 282-292, 2016.

15. Fenga C, Cacciola A, Rapisarda V, Spatari G, Calimeri S, Minciullo PL, Di Pasquale G and Gangemi S: Chlamydophila psittaci seropositivity and serum levels of soluble intercellular adhesion molecule-1 in farmers. Ann Agric Environ Med 15 277-280, 2008

16. Musumeci G, Cardile V, Fenga C, Caggia S and Loreto $C$ Mineral fibre toxicity: Expression of retinoblastoma $(\mathrm{Rb})$ and phospho-retinoblastoma $(\mathrm{pRb})$ protein in alveolar epithelial and mesothelial cell lines exposed to fluoro-edenite fibres. Cell Biol Toxicol 27: 217-225, 2011

17. Maira F, Catania A, Candido S, Russo AE, McCubrey JA, Libra M, Malaponte G and Fenga C: Molecular targeted therapy in melanoma: A way to reverse resistance to conventional drugs. Curr Drug Deliv 9: 17-29, 2012.

18. Rapisarda V, Marconi A, Candido S, Nicolosi D, Salmeri M, Gangemi P, Proietti L, Spandidos DA, Bracci M, Fenga C and Libra M: A tailored health surveillance program unveils a case of MALT lymphoma in an HCV-positive health-care worker. Oncol Lett 5: 651-654, 2013.

19. Candido S, Rapisarda V, Marconi A, Malaponte G, Bevelacqua V, Gangemi P, Scalisi A, McCubrey JA, Maestro R, Spandidos DA, et al: Analysis of the $B-R a f^{V 600 \mathrm{E}}$ mutation in cutaneous melanoma patients with occupational sun exposure. Oncol Rep 31: 1079-1082, 2014.

20. Malaponte G, Signorelli SS, Bevelacqua V, Polesel J, Taborelli M, Guarneri C, Fenga C, Umezawa K and Libra M: Increased Levels of NF- $\mathrm{KB}$-Dependent Markers in Cancer-Associated Deep Venous Thrombosis. PLoS One 10: e0132496, 2015.

21. Alavanja MC, Sandler DP, McMaster SB, Zahm SH, McDonnell CJ, Lynch CF, Pennybacker M, Rothman N, Dosemeci M, Bond AE, et al: The Agricultural Health Study. Environ Health Perspect 104: 362-369, 1996.

22. Corsini E, Sokooti M, Galli CL, Moretto A and Colosio C: Pesticide induced immunotoxicity in humans: A comprehensive review of the existing evidence. Toxicology 307 123-135, 2013.

23. García-García CR, Parrón T, Requena M, Alarcón R, Tsatsakis AM and Hernández AF: Occupational pesticide exposure and adverse health effects at the clinical, hematological and biochemical level. Life Sci 145: 274-283, 2016.

24. Simon-Delso N, Amaral-Rogers V, Belzunces LP, et al: Systemic insecticides (neonicotinoids and fipronil): Trends, uses, mode of action and metabolites. Environ Sci Pollut Res Int 22: 5-34, 2015.
25. Dhouib I, Jallouli M, Annabi A, Marzouki S, Gharbi N, Elfazaa S and Lasram MM: From immunotoxicity to carcinogenicity: The effects of carbamate pesticides on the immune system. Environ Sci Pollut Res Int 23: 9448-9458, 2016.

26. Weichenthal S, Moase C and Chan P: A review of pesticide exposure and cancer incidence in the Agricultural Health Study cohort. Environ Health Perspect 118: 1117-1125, 2010.

27. Gangemi S, Gofita E, Costa C, Teodoro M, Briguglio G, Nikitovic D, Tzanakakis G, Tsatsakis AM, Wilks MF, Spandidos DA and Fenga C: Occupational and environmental exposure to pesticides and cytokine pathways in chronic diseases (Review). Int J Mol Med 38: 1012-1020, 2016.

28. Groot MJ and Van't Hooft KE: The Hidden Effects of Dairy Farming on Public and Environmental Health in the Netherlands, India, Ethiopia, and Uganda, Considering the Use of Antibiotics and Other Agro-chemicals. Front Public Health 4: 12, 2016.

29. Maroni M, Fanetti AC and Metruccio F: Risk assessment and management of occupational exposure to pesticides in agriculture. Med Lav 97: 430-437, 2006.

30. Hernández Jerez AF, Gil F and Lacasaña M: Integrating epidemiological, mechanistic and experimental toxicology data for pesticide risk assessment. Toxicol Lett 258: S26, 2016.

31. Aprea C, Colosio C, Mammone T, Minoia C and Maroni M: Biological monitoring of pesticide exposure: A review of analytical methods. J Chromatogr B Analyt Technol Biomed Life Sci 769: 191-219, 2002.

32. Libich S, To JC, Frank R and Sirons GJ: Occupational exposure of herbicide applicators to herbicides used along electric power transmission line right-of-way. Am Ind Hyg Assoc J 45: 56-62, 1984.

33. Arbuckle TE, Cole DC, Ritter L and Ripley BD: Biomonitoring of herbicides in Ontario farm applicators. Scand J Work Environ Health 31 (Suppl 1): 90-97, discussion 63-65, 2005.

34. Rubino FM, Mandic-Rajcevic S, Ariano E, Alegakis A, Bogni M, Brambilla G, DePaschale G, Firmi A, Minoia C, Micoli G et al: Farmers' exposure to herbicides in North Italy: assessment under real-life conditions in small-size rice and corn. Toxicol Lett 210: 189-197, 2012.

35. Aprea C, Terenzoni B, De Angelis V, Sciarra G, Lunghini L, Borzacchi G, Vasconi D, Fani D, Quercia A, Salvan A and Settimi L: Evaluation of skin and respiratory doses and urinary excretion of alkylphosphates in workers exposed to dimethoate during treatment of olive trees. Arch Environ Contam Toxicol 48: 127-134, 2005.

36. Flack S, Goktepe I, Ball LM and Nylander-French LA: Development and application of quantitative methods for monitoring dermal and inhalation exposure to propiconazole. J Environ Monit 10: 336-344, 2008.

37. Vitali M, Protano C, Del Monte A, Ensabella F and Guidotti M: Operative modalities and exposure to pesticides during open field treatments among a group of agricultural subcontractors. Arch Environ Contam Toxicol 57: 193-202, 2009.

38. Organisation For Economic Co-Operation and Development: Guidance Document for the Conduct of Studies of Occupational Exposure to Pesticides During Agricultural Application. OECD Publishing, Paris, 2002.

39. Baldi I, Lebailly P, Jean S, Rougetet L, Dulaurent S and Marquet P: Pesticide contamination of workers in vineyards in France. J Expo Sci Environ Epidemiol 16: 115-124, 2006.

40. Baldi I, Lebailly P, Bouvier G, Rondeau V, Kientz-Bouchart V, Canal-Raffin M and Garrigou A: Levels and determinants of pesticide exposure in re-entry workers in vineyards: Results of the PESTEXPO study. Environ Res 132: 360-369, 2014.

41. Colosio C, Rubino FM, Alegakis A, Ariano E, Brambilla G, Mandic-Rajcevic S, Metruccio F, Minoia C, Moretto A, Somaruga $\mathrm{C}$ et al: Integration of biological monitoring, environmental monitoring and computational modelling into the interpretation of pesticide exposure data: introduction to a proposed approach. Toxicol Lett 213: 49-56, 2012.

42. Reffstrup TK, Larsen JC and Meyer O: Risk assessment of mixtures of pesticides. Current approaches and future strategies. Regul Toxicol Pharmacol 56:174-192, 2010.

43. Boverhof DR, Ladics G, Luebke B, Botham J, Corsini E, Evans E, Germolec D, Holsapple M, Loveless SE, Lu H, et al: Approaches and considerations for the assessment of immunotoxicity for environmental chemicals: a workshop summary. Regul Toxicol Pharmacol 68: 96-107, 2014.

44. Peters S, Vermeulen R, Portengen L, Olsson A, Kendzia B Vincent R, Savary B, Lavoué J, Cavallo D, Cattaneo A, et al: SYN-JEM: A Quantitative Job-Exposure Matrix for Five Lung Carcinogens. Ann Occup Hyg 60: 795-811, 2016. 
45. Alif SM, Dharmage SC, Bowatte G, Karahalios A, Benke G, Dennekamp M, Mehta AJ, Miedinger D, Künzli N, Probst-Hensch N, et al: Occupational exposure and risk of chronic obstructive pulmonary disease: A systematic review and meta-analysis. Expert Rev Respir Med 10: 861-872, 2016.

46. Milner A, Niedhammer I, Chastang JF, Spittal MJ and LaMontagne AD: Validity of a Job-Exposure Matrix for Psychosocial Job Stressors: Results from the Household Income and Labour Dynamics in Australia Survey. PLoS One 11: e0152980, 2016.

47. Carles C, Bouvier G, Lebailly P and Baldi I: Use of job-exposure matrices to estimate occupational exposure to pesticides: A review. J Expo Sci Environ Epidemiol: May 18, 2016 (Epub ahead of print)

48. Dosemeci M, Alavanja MC, Rowland AS, Mage D, Zahm SH, Rothman N, Lubin JH, Hoppin JA, Sandler DP and Blair A: A quantitative approach for estimating exposure to pesticides in the Agricultural Health Study. Ann Occup Hyg 46: 245-260, 2002.

49. Negatu B, Vermeulen R, Mekonnen Y and Kromhout H: A Method for Semi-quantitative Assessment of Exposure to Pesticides of Applicators and Re-entry Workers: An Application in Three Farming Systems in Ethiopia. Ann Occup Hyg 60 669-683, 2016

50. Fenga C, Gangemi S and Costa C: Benzene exposure is associated with epigenetic changes (Review). Mol Med Rep 13 $3401-3405,2016$

51. Orphanides $G$ and Reinberg D: A unified theory of gene expression. Cell 108: 439-451, 2002.

52. Grewal SI and Moazed D: Heterochromatin and epigenetic control of gene expression. Science 301: 798-802, 2003

53. Kouzarides T: Chromatin modifications and their function Cell 128: 693-705, 2007.

54. Jackson RJ and Standart N: How do microRNAs regulate gene expression? Sci STKE 2007: re1, 2007.

55. Collotta M, Bertazzi PA and Bollati V: Epigenetics and pesticides. Toxicology 307: 35-41, 2013.

56. Stouder C and Paoloni-Giacobino A: Specific transgenerational imprinting effects of the endocrine disruptor methoxychlor on male gametes. Reproduction 141: 207-216, 2011.

57. Holland N, Lizarraga D and Huen K: Recent progress in the genetics and epigenetics of paraoxonase: why it is relevant to children's environmental health. Curr Opin Pediatr 27: 240-247, 2015.

58. Lee BW, London L, Paulauskis J, Myers J and Christiani DC: Association between human paraoxonase gene polymorphism and chronic symptoms in pesticide-exposed workers. J Occup Environ Med 45: 118-122, 2003.

59. Matthews AR, Sutter ME and Rentz DE: Serum paraoxonase-1 (PON-1) genotype and exposure to organophosphorous insectides - is there a high-risk population? J Med Toxicol 7: 243-247, 2011

60. Costa C, Gangemi S, Giambò F, Rapisarda V, Caccamo D and Fenga C: Oxidative stress biomarkers and paraoxonase 1 polymorphism frequency in farmers occupationally exposed to pesticides. Mol Med Rep 12: 6353-6357, 2015.

61. Robertson KD: DNA methylation and human disease. Nat Rev Genet 6: 597-610, 2005 .

62. Tammen SA, Friso S and Choi SW: Epigenetics: The link between nature and nurture. Mol Aspects Med 34: 753-764, 2013

63. Howard TD, Hsu FC, Chen H, Quandt SA, Talton JW, Summers P and Arcury TA: Changes in DNA methylation over the growing season differ between North Carolina farmworkers and non-farmworkers. Int Arch Occup Environ Health 89: 1103-1110, 2016.

64. International Diabetes Federation (IDF): IDF Diabetes Atlas. 7th edition. IDF, Brussels, 2015.

65. Hu FB: Globalization of diabetes: The role of diet, lifestyle, and genes. Diabetes Care 34: 1249-1257, 2011.

66. Malekirad AA, Faghih M, Mirabdollahi M, Kiani M, Fathi A and Abdollahi M: Neurocognitive, mental health, and glucose disorders in farmers exposed to organophosphorus pesticides. Arh Hig Rada Toksikol 64: 1-8, 2013.

67. Montgomery MP, Kamel F, Saldana TM, Alavanja MC and Sandler DP: Incident diabetes and pesticide exposure among licensed pesticide applicators: Agricultural Health Study, 1993-2003. Am J Epidemiol 167: 1235-1246, 2008.

68. Starling AP, Umbach DM, Kamel F, Long S, Sandler DP and Hoppin JA: Pesticide use and incident diabetes among wives of farmers in the Agricultural Health Study. Occup Environ Med 71: 629-635, 2014
69. Jaacks LM and Staimez LR: Association of persistent organic pollutants and non-persistent pesticides with diabetes and diabetes-related health outcomes in Asia: A systematic review. Environ Int 76: 57-70, 2015.

70. Leso V, Capitanelli I, Lops EA, Ricciardi W and Iavicoli I Occupational chemical exposure and diabetes mellitus risk. Toxicol Ind Health: Mar 30, 2016 (Epub ahead of print).

71. Wilks MF: Pesticides and Parkinson's disease - What is the evidence from epidemiological and experimental studies? Toxicol Lett 258 (Suppl): S26-S27, 2016.

72. Elbaz A and Moisan F: The scientific bases to consider Parkinson's disease an occupational disease in agriculture professionals exposed to pesticides in France. J Epidemiol Community Health 70: 319-321, 2016

73. Yegambaram M, Manivannan B, Beach TG and Halden RU: Role of environmental contaminants in the etiology of Alzheimer's disease: a review. Curr Alzheimer Res 12: 116-146, 2015.

74. Kinsley L and Siddique T: Amyotrophic Lateral Sclerosis Overview. In: GeneReviews ${ }^{\circledR}$ [Internet]. Pagon RA, Adam MP, Ardinger HH, Wallace SE, Amemiya A, Bean LJH, Bird TD, Fong CT, Mefford HC, Smith RJH and Stephens K (eds). University of Washington, Seattle, WA, 1993-2016. Mar 23, 2001 [updated Feb 12, 2015].

75. Hernández AF, González-Alzaga B, López-Flores I and Lacasaña M: Systematic reviews on neurodevelopmental and neurodegenerative disorders linked to pesticide exposure: Methodological features and impact on risk assessment. Environ Int 92-93: 657-679, 2016.

76. Ritz BR, Paul KC and Bronstein JM: Of Pesticides and Men: A California Story of Genes and Environment in Parkinson's Disease. Curr Environ Health Rep 3: 40-52, 2016.

77. Wang A, Cockburn M, Ly TT, Bronstein JM and Ritz B: The association between ambient exposure to organophosphates and Parkinson's disease risk. Occup Environ Med 71: 275-281, 2014.

78. Freire Cand Koifman S: Pesticide exposure and Parkinson's disease: epidemiological evidence of association. Neurotoxicology 33: 947-971, 2012.

79. Dardiotis E, Xiromerisiou G, Hadjichristodoulou C, Tsatsakis AM, Wilks MF and Hadjigeorgiou GM: The interplay between environmental and genetic factors in Parkinson's disease susceptibility: The evidence for pesticides. Toxicology 07: 17-23, 2013.

80. Vinken M: The adverse outcome pathway concept: A pragmatic tool in toxicology. Toxicology 312: 158-165, 2013.

81. Groh KJ, Carvalho RN, Chipman JK, Denslow ND, Halder M, Murphy CA, Roelofs D, Rolaki A, Schirmer K and Watanabe KH: Development and application of the adverse outcome pathway framework for understanding and predicting chronic toxicity: I. Challenges and research needs in ecotoxicology. Chemosphere 120: 764-77, 2015.

82. European Food Safety Authority (EFSA): Investigation into experimental toxicological properties of plant protection products having a potential link to Parkinson's disease and childhood leukaemia. EFSA Journal, Parma, 2016.

83. Kamel F, Umbach DM, Bedlack RS, Richards M, Watson M, Alavanja MC, Blair A, Hoppin JA, Schmidt S and Sandler DP: Pesticide exposure and amyotrophic lateral sclerosis. Neurotoxicology 33: 457-462, 2012.

84. Kang H, Cha ES, Choi GJ and Lee WJ: Amyotrophic lateral sclerosis and agricultural environments: A systematic review. J Korean Med Sci 29: 1610-1617, 2014.

85. González-Alzaga B, Lacasaña M, Aguilar-Garduño C, Rodríguez Barranco M, Ballester F, Rebagliato $\mathrm{M}$ and Hernández AF: A systematic review of neurodevelopmental effects of prenatal and postnatal organophosphate pesticide exposure. Toxicol Lett 15: 104-121, 2014.

86. Muñoz-Quezada MT, Lucero BA, Barr DB, Steenland K, Levy K, Ryan PB, Iglesias V, Alvarado S, Concha C, Rojas E, et al: Neurodevelopmental effects in children associated with exposure to organophosphate pesticides: A systematic review. Neurotoxicology 39: 158-168, 2013.

87. Reynolds LP and Caton JS: Role of the pre- and post-natal environment in developmental programming of health and productivity. Mol Cell Endocrinol 6: 54-59, 2012

88. Hanke W and Jurewicz J: The risk of adverse reproductive and developmental disorders due to occupational pesticide exposure: An overview of current epidemiological evidence. Int J Occup Med Environ Health 17: 223-243, 2004.

89. Kumar S: Occupational exposure associated with reproductive dysfunction. J Occup Health 46: 1-19, 2004. 
90. Arbuckle TE, Lin Z and Mery LS: An exploratory analysis of the effect of pesticide exposure on the risk of spontaneous abortion in an Ontario farm population. Environ Health Perspect 109: 851-857, 2001.

91. Jurewicz J, Hanke W and Makowiec-Dabrowska T: Low risk of reproductive disorders among female greenhouse workers - safe work conditions or health selection for the light work? Med Pr 59: 123-131, 2008 (In Polish).

92. Jurewicz $\mathbf{J}$ and Hanke W: Risk of reproductive disorders in greenhouse workers. Med Pr 58: 433-438, 2007 (In Polish).

93. Miranda-Contreras L, Cruz I, Osuna JA, Gómez-Pérez R, Berrueta L, Salmen S, Colmenares M, Barreto S, Balza A, Morales Y, et al: Effects of occupational exposure to pesticides on semen quality of workers in an agricultural community of Merida state, Venezuela. Invest Clin 56: 123-136, 2015 (In Spanish).

94. Radwan M, Jurewicz J, Wielgomas B, Piskunowicz M, Sobala W, Radwan P, Jakubowski L, Hawuła W and Hanke W: The association between environmental exposure to pyrethroids and sperm aneuploidy. Chemosphere 128: 42-48, 2015.

95. Jamal F, Haque QS, Singh S and Rastogi S: The influence of organophosphate and carbamate on sperm chromatin and reproductive hormones among pesticide sprayers. Toxicol Ind Health 32: 1527-1536, 2015.

96. Neghab M, Momenbella-Fard M, Naziaghdam R, Salahshour N, Kazemi M and Alipour $\mathrm{H}$ : The effects of exposure to pesticides on the fecundity status of farm workers resident in a rural region of Fars province, southern Iran. Asian Pac J Trop Biomed 4: 324-328, 2014.

97. Polesel J, Franceschi S, Talamini R, Negri E, Barzan L, Montella M, Libra M, Vaccher E, Franchin G, La Vecchia C, et al: Tobacco smoking, alcohol drinking, and the risk of different histological types of nasopharyngeal cancer in a low-risk population. Oral Oncol 47: 541-545, 2011.

98. Clapp RW, Jacobs MM and Loechler EL: Environmental and occupational causes of cancer: New evidence 2005-2007. Rev Environ Health 23: 1-37, 2008.

99. Del Pup L, Mantovani A, Luce A, Cavaliere C, Facchini G, Di Francia R, Caraglia M and Berretta M: Endocrine disruptors and female cancer: Informing the patients (Review). Oncol Rep 34: 3-11, 2015.
100. Schinasi L and Leon ME: Non-Hodgkin lymphoma and occupational exposure to agricultural pesticide chemical groups and active ingredients: a systematic review and meta-analysis. Int J Environ Res Public Health 11: 4449-4527, 2014.

101. Lewis-Mikhael AM, Bueno-Cavanillas A, Ofir Guiron T, Olmedo-Requena R, Delgado-Rodríguez M and JiménezMoleón JJ: Occupational exposure to pesticides and prostate cancer: A systematic review and meta-analysis. Occup Environ Med 73: 134-144, 2016

102. Doolan G, Benke G and Giles G: An update on occupation and prostate cancer. Asian Pac J Cancer Prev 15: 501-516, 2014.

103. Sokolosky ML, Stadelman KM, Chappell WH, Abrams SL, Martelli AM, Stivala F, Libra M, Nicoletti F, Drobot LB, Franklin RA, et al: Involvement of Akt-1 and mTOR in sensitivity of breast cancer to targeted therapy. Oncotarget 2: 538-550, 2011.

104. McCubrey JA, Abrams SL, Ligresti G, Misaghian N, Wong EW, Steelman LS, Bäsecke J, Troppmair J, Libra M, Nicoletti F, et al: Involvement of p53 and Raf/MEK/ERK pathways in hematopoietic drug resistance. Leukemia 22: 2080-2090, 2008.

105. McCubrey JA, Steelman LS, Franklin RA, Abrams SL, Chappell WH, Wong EW, Lehmann BD, Terrian DM, Basecke J, Stivala F, et al: Targeting the RAF/MEK/ERK, PI3K/AKT and p53 pathways in hematopoietic drug resistance. Adv Enzyme Regul 47: 64-103, 2007.

106. Hernández AF and Menéndez P: Linking Pesticide Exposure with Pediatric Leukemia: Potential Underlying Mechanisms. Int J Mol Sci 17: 461, 2016.

107. Fenga C, Gangemi S, Catania S, De Luca A and Costa C: IL-17 and IL-22 serum levels in greenhouse workers exposed to pesticides. Inflamm Res 63: 895-897, 2014.

108. Costa C, Rapisarda V, Catania S, Di Nola C, Ledda C and Fenga C: Cytokine patterns in greenhouse workers occupationally exposed to $\alpha$-cypermethrin: An observational study. Environ Toxicol Pharmacol 36: 796-800, 2013. 